\title{
Comparative behavior of red lionfish Pterois volitans on native Pacific versus invaded Atlantic coral reefs
}

\author{
Katherine Cure ${ }^{1,4, *}$, Cassandra E. Benkwitt ${ }^{2}$, Tye L. Kindinger ${ }^{2}$, Emily A. Pickering ${ }^{2}$, \\ Timothy J. Pusack ${ }^{2}$, Jennifer L. McIlwain ${ }^{1,3}$, Mark A. Hixon ${ }^{2}$ \\ ${ }^{1}$ The Marine Laboratory, University of Guam, Mangilao, Guam 96923, USA \\ ${ }^{2}$ Department of Zoology, Oregon State University, Corvallis, Oregon 97331-2914, USA \\ ${ }^{3}$ Department of Environment and Agriculture, Curtin University, Perth, Western Australia 6845, Australia \\ ${ }^{4}$ Present address: School of Plant Biology, The University of Western Australia, Crawley, Western Australia 6009, Australia
}

\begin{abstract}
Pacific red lionfish Pterois volitans have invaded Atlantic reefs and reached much greater population densities than on native reefs. We hypothesized that lionfish on invaded reefs would (1) experience higher kill rates and thus spend less time hunting, given the naïveté of Atlantic prey, (2) consume a greater variety of prey, given the lack of native prey defenses, and (3) display less pronounced crepuscular patterns of hunting, given the ease of capturing Atlantic prey. Comparative behavioral observations were conducted in 2 native regions (Philippines and Guam) and 2 invaded regions (Cayman Islands and Bahamas) to assess lionfish time budgets and diurnal activity patterns and to explore correlations between environmental variables and lionfish behavior. Contrary to our first hypothesis, total time allocated to hunting and kill rates showed no difference between native and invaded reefs, despite considerable regional variation. However, Atlantic prey of lionfish were twice as large as Pacific prey, suggesting that despite similar hunting behavior, invasive lionfish ingest greater daily rations of prey biomass. Furthermore, consistent with our second hypothesis, lionfish on invaded reefs had broader diets, and also relied less on 'blowing' behavior for prey capture, pointing to substantial prey naïveté in the invaded range. Importantly, only in the invaded range did we observe lionfish consuming parrotfishes, the decline of which could have indirect effects on interactions between seaweeds and corals. Finally, lionfish overall tended to exhibit a crepuscular pattern in behavior whereby hunting peaked at sunrise and/or sunset, with no differences attributable to native vs. invasive status.
\end{abstract}

KEY WORDS: Native vs. invasive behavior - Diurnal hunting pattern - Crepuscular hunting · Time budget

\section{INTRODUCTION}

In the mid-1980s Pacific red lionfish Pterois volitans invaded the Western Atlantic via the aquarium trade (Semmens et al. 2004), and beginning in the early 2000s extended their range throughout the Caribbean, Gulf of Mexico, and down the South American coastline (Schofield 2010). Despite local attempts at removal, invasive lionfish have reached local population densities far greater than in their native Pacific (Whitfield et al. 2007, Green \& Côté 2008, Kulbicki et al. 2012). At invaded locations, lionfish consume a broad diversity of small fishes and crustaceans including juveniles of herbivores (Morris \& Akins 2009) and have caused substantial reductions in the recruitment and abundance of reef fishes 
(Albins \& Hixon 2008, Green et al. 2012). Invasive lionfish can also negatively affect native piscivorous predators through both predation on juveniles and competition with adults (Albins 2012). Thus, lionfish may ultimately cause drastic changes in Atlantic coral-reef ecosystems (Albins \& Hixon 2011).

Lionfish are likely protected from predators by their cryptic coloration and numerous venomous spines (Allen \& Eschmeyer 1973). Predators rarely target adult lionfish at either native or invaded locations, despite anecdotal evidence of occasional predation (Bernadsky \& Goulet 1991, Maljković \& Van Leeuwen 2008). Because natural controls have not been definitively identified in either the native Pacific or invaded Atlantic, direct removals of lionfish by humans have to date been the only effective way to reduce invasive populations; however invasive lionfish are widespread geographically and occur far deeper than usual SCUBA depths (Whitfield et al. 2007, Lesser \& Slattery 2011), so complete eradication is unlikely.

Before the invasion, little was known about the ecology and behavior of lionfish, due in part to their rarity in their native range (Kulbicki et al. 2012). Lionfish use 2 types of hunting methods: slow stalking of prey aided by fanlike pectoral fins that herd prey, and sit-and-wait ambush (Randall 2005). Blowing behavior, by which lionfish produce jets of water directed at prey while approaching them, enhances predatory efficiency by confusing or distracting prey (Albins \& Lyons 2012). Lionfish diets are well documented in the invaded range and include a broad variety of coral reef fishes, crustaceans (Morris \& Akins 2009, Côté \& Maljković 2010, Green et al. 2012), and even conspecifics (Valdez-Moreno et al. 2012). These records coincide with diet reported from qualitative descriptions in the native range (Myers 1999). Hunting takes place during crepuscular periods (Myers 1999, Randall 2005) when low light levels impede visually adapted prey (Helfman 1986). During the daytime, native lionfish become inactive in holes and crevices (Fishelson 1997), a pattern common to a variety of other predatory fishes and often influenced by ambient light levels (Belovsky \& Slade 1986). Invasive lionfish in the Bahamas also display this crepuscular pattern of hunting behavior (Green et al. 2011).

Behavioral comparisons between populations in native vs. invaded ranges are highly informative because they may identify factors that foster invasion success (Holway \& Suarez 1999, Morris \& Whitfield 2009, Meyer \& Dierking 2011), and may help in developing control measures (Guo 2006). Changes in diel activity of fishes are a common response to differences in biotic and abiotic environmental factors, including predator abundance, prey availability, presence/absence of competitors, habitat structure, depth, and abiotic conditions such as temperature and light levels (Chen et al. 1999, Reebs 2002, Hansen et al. 2004, Andrews et al. 2009, Côté \& Maljković 2010). Because these factors may vary regionally, and because invasion is often accompanied by release from the natural controls of competition and predation (Mack et al. 2000), behavioral differences in invasive species are therefore likely between native and invaded locations. For invasive predators, such differences can mean access to more abundant or higher quality prey (Meyer \& Dierking 2011), enhanced by the substantial advantages novel invasive predators usually have over naïve native prey (Cox \& Lima 2006).

We conducted replicate comparative field observations in 2 regions in the native Pacific Ocean and 2 regions in the invaded Atlantic Ocean in an effort to determine whether there are any inter-ocean differences in lionfish behavior. Assuming native Atlantic prey are naïve to invasive lionfish, we hypothesized that lionfish would have higher success at killing prey in invaded regions. If so, we further hypothesized that higher success at killing prey would result in concomitant changes to predatory behavior in the invaded Atlantic, including less time spent hunting as lionfish reach satiation more rapidly, and hunting being less restricted to the low-light levels of crepuscular times often exploited by native predators (Helfman 1986). We also predicted that, as an efficient and voracious generalist predator, lionfish would consume a greater variety of prey in their invaded Atlantic range compared to their native Pacific range.

\section{MATERIALS AND METHODS}

\section{Data collection}

We observed in situ behavior of lionfish in 2 regions within each ocean: the Philippines and Guam in the native range, and the Cayman Islands and the Bahamas in the invaded range (Fig. 1). Invasive lionfish were first detected in the Bahamas in 2004 and in the Caymans in 2008 (Schofield 2009). Sampling was conducted over a 3-yr period, mostly during June to September 2009-2011. We selected sites known to have lionfish, including sandy slopes with coral patches, continuous reef walls, and a few artificial 


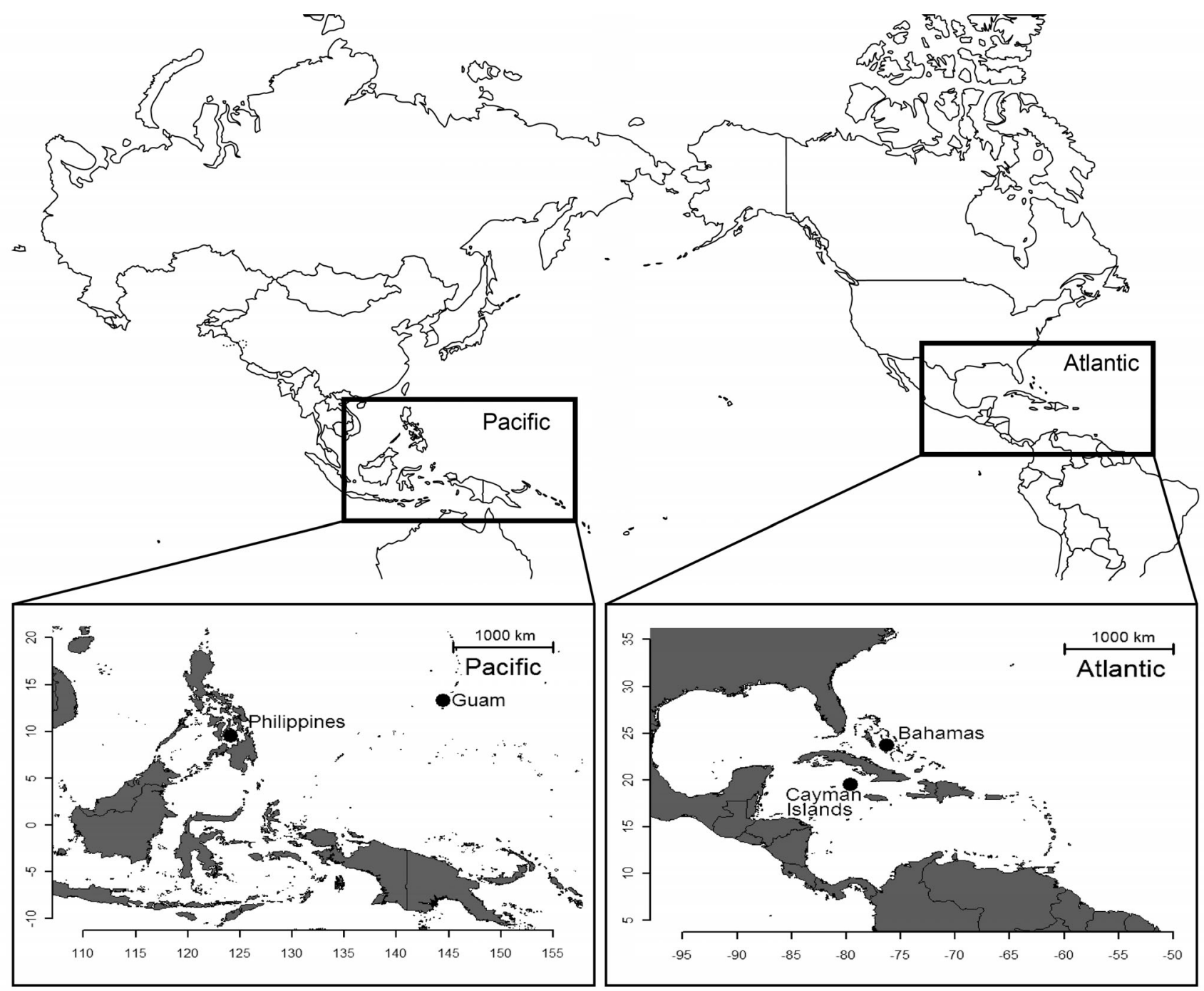

Fig. 1. Regions sampled for lionfish Pterois volitans behavior: the Philippines and Guam in the Pacific Ocean, and the Cayman Islands and Bahamas in the Atlantic Ocean

habitats (e.g. piers, small wrecks, tire reefs, and old fish traps). Maximum depth at these sites was $25 \mathrm{~m}$.

The number of sites sampled depended on lionfish frequency encountered at those sites. In the native range, where the probability of encountering lionfish was low, 20 sites were sampled in the Philippines and 13 on Guam. In the invasive range, 5 sites were sampled in the Bahamas and 4 in the Cayman Islands.

Because capturing and tagging lionfish observed in this study was logistically impractical, and because tagging can possibly alter lionfish behavior towards the observer (authors' pers. obs.), we chose to observe untagged animals. At each site during any given time of day, we ensured that different animals were sampled by swimming over the site unidirectionally and sampling lionfish encountered haphaz- ardly along the way. Each site was sampled only once within a day, and if we returned to that same site on another day, we sampled different parts of the site and different time periods. Therefore, we assumed that our observations were statistically independent and representative, even when we had no way of knowing with certainty whether we had resampled the same fish between days.

In each region, we conducted a series of standardized 10-min observations taken from sunrise to sunset (between 06:00 and 18:30 h). During each period, lionfish behavior was recorded by trained observers using either SCUBA or snorkel. There were 5 observers in the native range and 8 in the invaded range (1 observer in the Pacific and 2 observers in the Atlantic completed $60 \%$ of the total 
observations). Care was taken to minimize the influence of observer presence on lionfish behavior by keeping a distance of approximately $3 \mathrm{~m}$ from each fish. We attempted to sample equally all times of day, sites, habitats and environmental conditions, subject to logistic constraints.

Eight lionfish behaviors were quantified, following an initial ethogram constructed from a pilot study in the Bahamas. Behaviors were quantified as either proportion of time (i.e. proportion of each 10-min observation period) or counts (i.e. number of events per each 10-min observation period). Proportion of time was recorded for each of 4 activities: inactive, minimal activity, active, and hunting. The first 3 range from lionfish being stationary, to short distance movements, to long distance movements, respectively, but in all instances pectoral fins are relaxed (i.e. not flared and in position for hunting). Hunting activity was obvious as lionfish focused on particular prey with fully flared pectoral fins (Green et al. 2011). Counts were recorded for aggressive interactions (chasing other lionfish or other fish species), strikes (successful and unsuccessful attacks on potential prey), kills (successful capture of prey, i.e. prey consumed), and blows (water current directed at prey). During each observation period, we identified all prey approached by lionfish to at least the family level as well as the species level where possible, and estimated prey body size as total length (TL) to the nearest $\mathrm{cm}$.

For each 10-min observation we also measured 5 environmental variables known to influence fish behavior. (1) We recorded the microhabitat within which each observation occurred, mostly hard coral, rock-boulder/cave and sand/rubble, and less frequently seagrass beds, sponge fields, soft coral fields, and artificial structures. Lionfish usually did not move outside of the identified microhabitat during the observation time. In the few cases where such movement did occur, microhabitat was classified as the area where lionfish spent most of the observation time. During each sample period, we also recorded (2) cloud cover (clear: 0-25\%, partly cloudy: 25$75 \%$, overcast: $>75 \%$ ), (3) current (low: diver barely kicking to maintain position, medium: periodic kicking required by diver to maintain position, high: constant kicking by diver required to maintain position), (4) estimated lionfish size (TL) and (5) depth. Temperature was measured in situ using $\mathrm{HOBO}{ }^{\circledR}$ temperature loggers every $30 \mathrm{~min}$ in Guam and the Bahamas, while temperature data for the Philippines and the Cayman Islands were recorded from NOAA virtual stations (http://coralreefwatch.noaa. gov/satellite/current/products_vs.html).

\section{Statistical analyses}

Frequency distributions for each of the quantified behaviors were highly skewed and had high proportions of ones and zeros, so data transformation did not result in either normality or homoscedasticity. The 2 most common behaviors (inactive and hunting), were therefore analyzed with a logistic regression using a generalized linear mixed-effects model, in which region (random effect) was nested within ocean (fixed effect). The model was robust to the skewed nature of the data and allowed us to explore the cumulative effects of putative explanatory variables. Cumulative effects of ocean, time period, habitat, cloud cover, current, lionfish size (TL), and depth on lionfish behavior were assessed.

Despite the reduction in detail from the conversion of proportions to binary data, a logistic regression model was chosen in part because a lionfish that is exhibiting inactivity or hunting is doing so exclusively (i.e. if a lionfish is inactive, it cannot hunt, and vice versa). The behaviors categorized as 'minimal activity' and 'active' (both not involving hunting) accounted for less than $10 \%$ of the total time budgets for all regions, so these were excluded from further analysis, as well as rates of aggressive behavior toward conspecifics, which were very low in all regions.

Data for $y$ were binary variables created for lionfish behavior ( 0 inactive and $1=$ hunting). An observation was considered as inactive if $>50 \%$ of the 10 -min period was spent inactive, and as hunting if $>50 \%$ of the 10 -min period was spent hunting; $75 \%$ of all observation periods were dominated by one behavior or the other (i.e. either hunting or inactive represented $>80 \%$ of the observation period). All logistic regressions were done in $\mathrm{R}$ ( $\mathrm{R}$ Development Core Team 2010) using the package 'Ime4' (Bates et al. 2011) and following the guidelines of Rossiter \& Loza (2010) and Peng et al. (2002). Model fit was assessed by examination of model residuals, predicted outcomes, likelihood ratio tests and chi-square statistics (Quinn \& Keough 2002). Validation of the model by comparing predicted probabilities to observed outcomes was also performed $(70 \%$ of outcomes were correctly predicted by the model).

Partitioning of variance to determine the relative importance of each explanatory variable in the model was calculated using the $\mathrm{R}$ package 'hier.part' (Walsh \& MacNally 2008). Hierarchical partitioning is a technique that, rather than seeking a best fit, uses all possible models in a regression hierarchy to distinguish variables that have the 
highest independent correlations with the response variable; these are most likely to influence variation (MacNally 1996).

One-way univariate permutational analyses of variance (PERMANOVA; Anderson et al. 2008) were used to compare strike and kill rate means at the level of ocean vs. ocean, with region nested within ocean. These were chosen because of their robustness to deviations from normality and homoscedasticity, characteristic of our data. PERMANOVAs were run for 9999 permutations in PRIMER 6 (PRIMER-E Ltd.) with the following specifications: Euclidean distance, sequential sums of squares, and permutation of residuals under the reduced model (Anderson et al. 2008).

\section{RESULTS}

We observed lionfish ranging in size from 5 to $35 \mathrm{~cm}$ TL during a total of $192 \mathrm{~h}$ of time budgeting at native reefs (Philippines $37 \mathrm{~h}$, Guam $28 \mathrm{~h}$ ) and invaded reefs (Cayman Islands 73 h, Bahamas 54 h). Variation in lionfish time budgets was not substantial between oceans, but considerable between regions within each ocean (Fig. 2, Table 1). Lionfish were usually more active in the Philippines (native) and the Cayman Islands (invaded), and more sedentary in Guam (native) and the Bahamas (invaded). In all regions, we never observed predators attacking lionfish. Temperature was similar both between oceans (pooling regional means $\pm \mathrm{SE}$ : Pacific $=28.13 \pm$ $0.02^{\circ} \mathrm{C}$, Atlantic $=28.69 \pm 0.01^{\circ} \mathrm{C}$ ) and between regions within oceans (mean $\pm \mathrm{SE}$ : Philippines $=$
Table 1. Results of logistic regressions of lionfish Pterois volitans time budgets between the native Pacific Ocean and the invaded Atlantic Ocean, using a general linear mixedeffects model. Shown are coefficient estimates $(\beta)$ for each explanatory variable together with standard errors (SE), significance $(p)$ and odds ratios $\left(e^{\beta}\right)$. Also presented are the independent effects (IE) of each explanatory variable (\%) on the dependent variable (lionfish behavior), calculated by hierarchical partitioning. p-values in bold are significant. Likelihood ratio and chi-square test statistics indicate logistic regression model fit. Reference levels for this regression were set as Atlantic for ocean, sunrise for time of day, hard coral for habitat, clear for weather, and high for current

\begin{tabular}{|c|c|c|c|c|c|}
\hline Coefficient & $\beta$ & SE & $\mathrm{p}$ & $e^{\beta}$ & IE $(\%)$ \\
\hline Intercept & -0.003 & 0.773 & 0.997 & & \\
\hline Ocean & & & & & 3.754 \\
\hline Pacific & 0.438 & 0.891 & 0.623 & 1.549 & \\
\hline Time of day & & & & & 35.626 \\
\hline Morning & -2.557 & 0.244 & $<0.001$ & 0.078 & \\
\hline Midday & -2.446 & 0.279 & $<0.001$ & 0.087 & \\
\hline Afternoon & -1.748 & 0.216 & $<0.001$ & 0.174 & \\
\hline Sunset & -0.719 & 0.271 & 0.008 & 0.487 & \\
\hline Habitat & & & & & 13.715 \\
\hline Other & 0.434 & 0.259 & 0.094 & 1.543 & \\
\hline Rock-boulder & -0.479 & 0.239 & 0.045 & 0.619 & \\
\hline Sand-rubble & 0.451 & 0.271 & 0.096 & 1.569 & \\
\hline Cloud cover & & & & & 7.567 \\
\hline Overcast & 0.687 & 0.227 & 0.002 & 1.988 & \\
\hline Partly cloudy & -0.158 & 0.184 & 0.389 & 0.854 & \\
\hline Current & & & & & 9.570 \\
\hline Low & 1.210 & 0.326 & $<0.001$ & 3.355 & \\
\hline Medium & 1.125 & 0.346 & 0.001 & 3.079 & \\
\hline Size & & & & & 10.055 \\
\hline & -0.014 & 0.013 & 0.102 & 0.258 & \\
\hline Depth & & & & & 19.712 \\
\hline & 0.028 & 0.024 & 0.499 & 0.241 & \\
\hline \multirow{2}{*}{\multicolumn{3}{|c|}{ Likelihood ratio test statistic }} & \multicolumn{3}{|c|}{$420.736, \mathbf{p}<\mathbf{0 . 0 0 1}$} \\
\hline & & & \multicolumn{3}{|c|}{$1092.019, \mathrm{p}=0.727$} \\
\hline
\end{tabular}

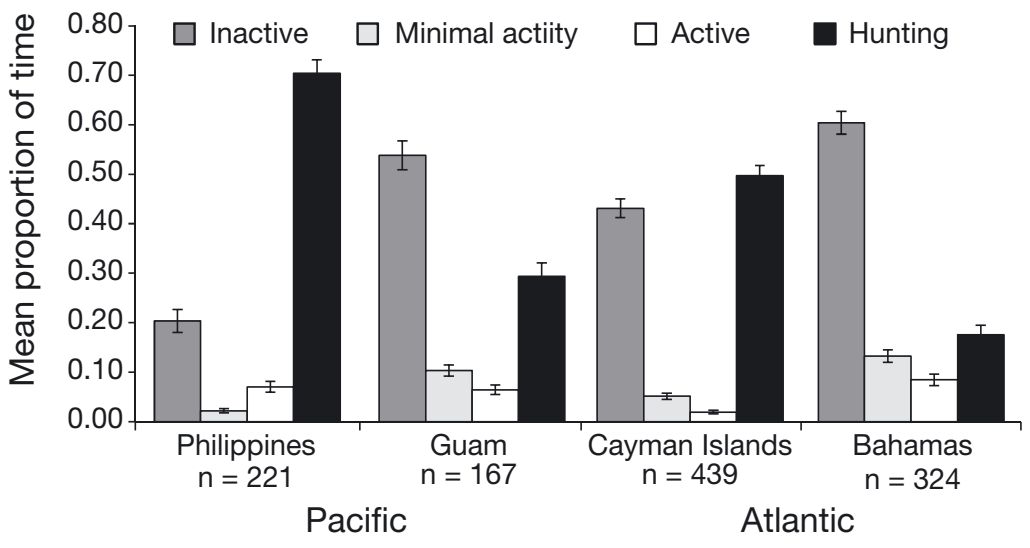

Fig. 2. Pterois volitans. Time budget summaries for lionfish in each of 4 regions, 2 per ocean. Shown are mean proportions $( \pm \mathrm{SEM}, \mathrm{n}=$ no. of 10 -min samples) of dawn-to-dusk time in each of the 4 activities recorded (inactive, minimal activity, active and hunting)
$30.23 \pm 0.04^{\circ} \mathrm{C}$, Guam $=28.12 \pm 0.01^{\circ} \mathrm{C}$, Cayman Islands $=29.72 \pm 0.06^{\circ} \mathrm{C}$, Bahamas $=28.68 \pm 0.02^{\circ} \mathrm{C}$ )

\section{Hunting behavior and prey consumed}

Lionfish hunting behavior contradicted a priori expectations of interocean differences. Time spent hunting throughout the day was equal between the Atlantic and the Pacific (Table 1), although maximum hunting time was nonetheless observed in the Pacific (Philippines $=70 \%$ hunting) and minimum hunting time in the Atlantic (Bahamas $=17.6 \%$ hunting) (Fig. 2). 
Diurnal patterns of lionfish behavior showed that, irrespective of native vs. invaded range, hunting was greater and inactivity lower during sunrise and/or sunset (Fig. 3, Table 1). A strongly crepuscular hunting pattern was most evident for lionfish in Guam and the Bahamas, while lionfish hunting in the Philippines and the Cayman Islands peaked at sunrise (Fig. 3a,c).

Also contradicting expectations, both strike and kill rates were similar between oceans (strikes: pseudo- $F=0.051, \mathrm{df}=1,1146, \mathrm{p}=1$; kills: pseudo- $F=$ 0.081, df =1,1146, $\mathrm{p}=0.834$ ) (Fig. 4a), although there was considerable regional variation. Successful kill rates ( $\%$ of total strikes that resulted in prey being consumed $=$ [number of kills/number of strikes] $\times$ 100) were highest in the Bahamas (51.2\%), followed by Philippines $(50.0 \%)$, the Cayman Islands $(25.6 \%)$, and Guam (22.9\%) (Fig. 4a).

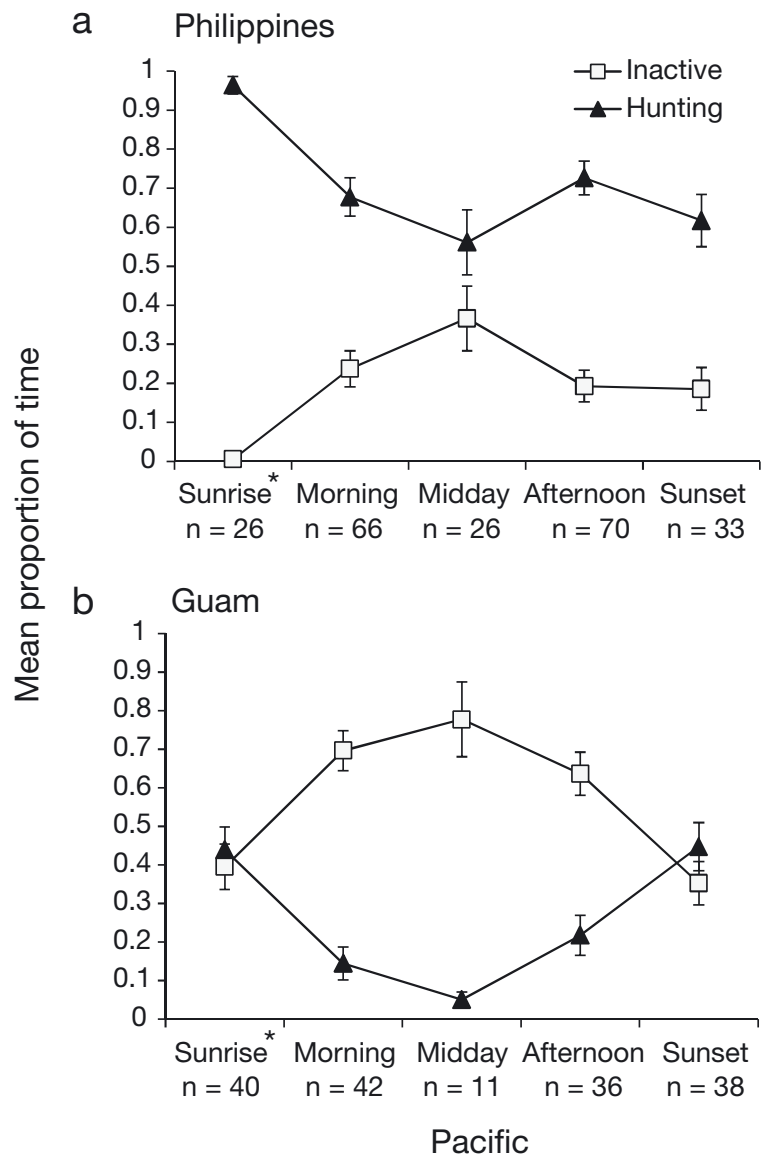

Despite lionfish time budgets and kill rates varying more between regions than between oceans, there were several clear differences in hunting behavior between the native Pacific and invaded Atlantic ranges. First, mean blowing rates were 3 times lower in the invaded range vs. the native range (Fig. 4b). Second, mean prey size was nearly double in the invaded vs. the native range (mean \pm SEM: Atlantic $=$ $2.45 \pm 0.42 \mathrm{~cm}$, Pacific $=1.50 \pm 0.35 \mathrm{~cm})$. Third, observed diets (kill rates) were broader in the invaded range than in the native range (no. of prey taxa killed per $1000 \mathrm{~min}$ : Atlantic $=1.6$, Pacific $=0.9$ ), even though strikes targeted a greater diversity of fishes in the native Pacific (no. of prey taxa targeted per 1000 min: Atlantic $=2.5$, Pacific $=3.8$ ). Lionfish successfully killed prey in 6 fish families in the invaded range (Apogonidae, Blenniidae, Gobiidae, Labridae, Pomacentridae and Scaridae), vs. only 2 in
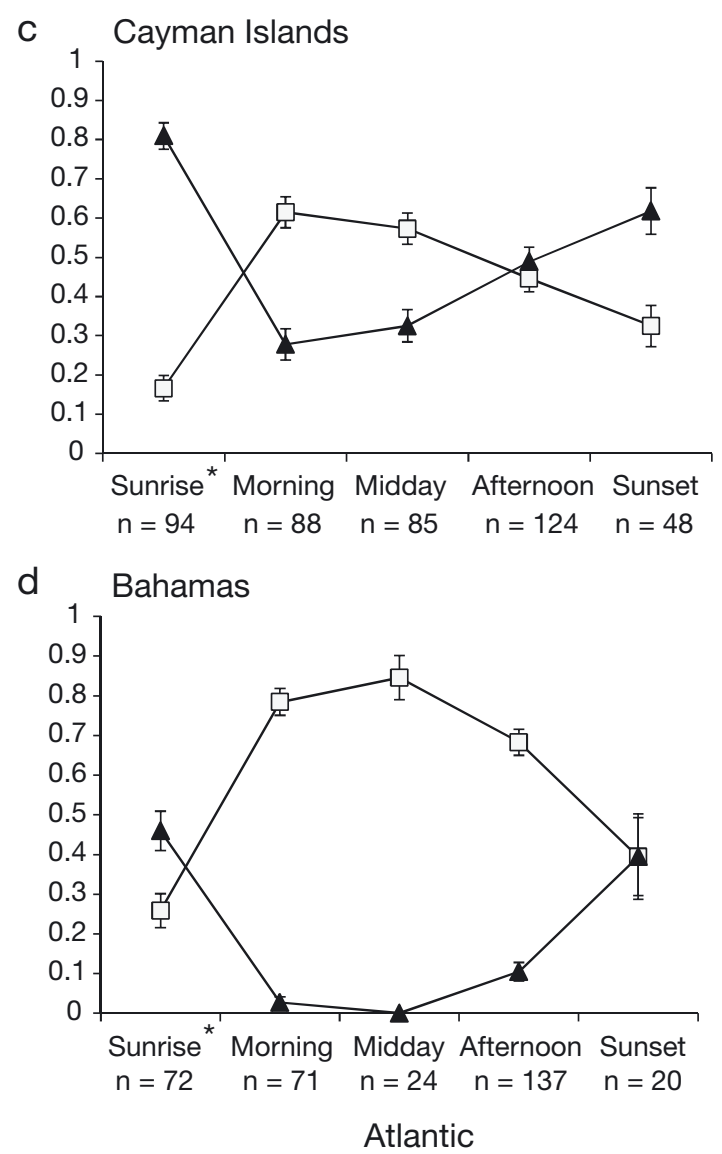

Fig. 3. Pterois volitans. Time budgets of lionfish across time of day for inactivity and hunting behavior at each of the 4 regions: (a) Philippines, (b) Guam, (c) Cayman Islands, and (d) Bahamas. Shown are mean ( \pm SEM) proportions of time spent in each behavior, standardized to regional sunrise and sunset times (sunrise: sunrise to $2 \mathrm{~h}$ after sunrise; morning: 2 to $5 \mathrm{~h}$ after sunrise; midday: ca. 3-h period midway between sunrise and sunset; afternoon: 2 to $5 \mathrm{~h}$ before sunset; sunset: $2 \mathrm{~h}$ before sunset to sunset). $\mathrm{n}=$ no. of 10 -min samples. Asterisk $\left({ }^{*}\right)$ next to sunrise represents significant differences in activity levels for this time period $(\mathrm{p}<0.01$; see Table 1$)$ 


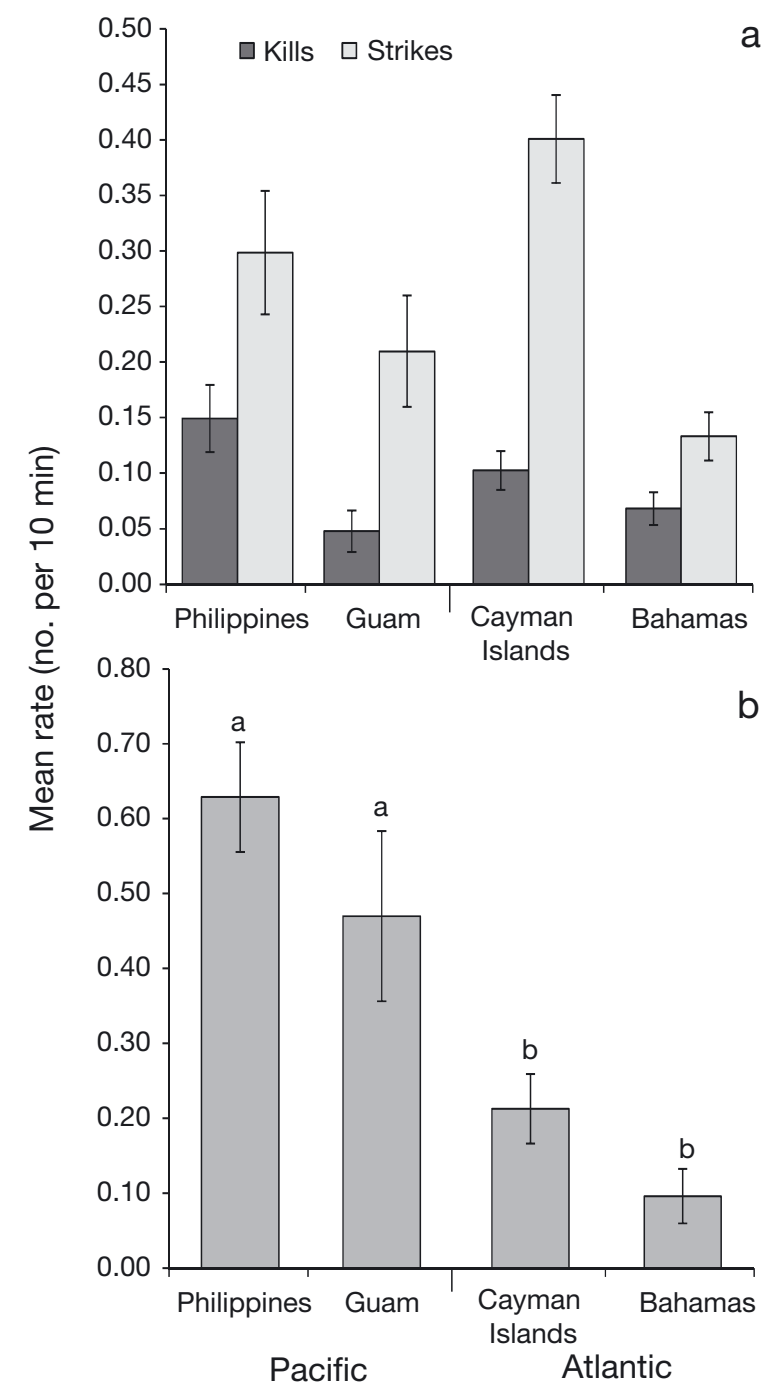

Fig. 4. Pterois volitans. Comparison of mean $( \pm$ SEM) (a) strike rates (successful and unsuccessful) and kill rates (successful strikes, i.e. prey consumed), and (b) blow rates of lionfish in the Pacific (left) and Atlantic (right). For (b) lowercase letters denote significant differences in blow rates between Pacific and Atlantic Oceans (pseudo- $F=13.234$, $\mathrm{df}=1,1113, \mathrm{p}=0.001)$

the native range (Pomacentridae and Trichonotidae) (Table 2). Strikes were mostly towards gobies (Gobiidae), wrasses (Labridae) and parrotfishes (Scaridae) in the invaded range, and towards cardinalfishes (Apogonidae), gobies, and marine catfishes (Plotosidae) in the native Pacific. Successful kills in the Atlantic included ecologically important species such as juvenile parrotfishes, which were not targeted by lionfish in the Pacific. These differences in diet breadth occurred despite the fact that there are far more potential prey fish species in the native range compared to the invaded range of lionfish (Roberts et al. 2002).

\section{Lionfish size}

Overall, body size had no statistical effect on lionfish behavior (Table 1). However, the coefficient estimate for size was negative, suggesting that smaller lionfish spent more time hunting $(\beta=-0.014, \mathrm{p}=$ 0.102 ; Table 1). Furthermore, when individual regions were analyzed separately, smaller lionfish (5 to $15 \mathrm{~cm} \mathrm{TL}$ ) in the Philippines and the Cayman Islands spent more time hunting than larger fish (Spearman rank correlations: $\beta=-0.145, p=0.040$ for the Philippines; $\beta=-0.131, p=0.036$ for the Cayman Islands). Lionfish size distributions differed across regions, with larger lionfish found in Guam and the Bahamas (mean $\pm \mathrm{SD}$ : Philippines $=17.69 \pm 6.15 \mathrm{~cm}$ TL, Guam $=22.08 \pm 7.22 \mathrm{~cm} \mathrm{TL}$, Cayman Islands $=$ $15.63 \pm 5.57 \mathrm{~cm} \mathrm{TL}$, Bahamas $=22.66 \pm 5.44 \mathrm{~cm} \mathrm{TL}$; Kruskal-Wallis $H=219.191, \mathrm{df}=3,1146, \mathrm{p}<0.001$ ).

\section{Environmental effects}

Between-ocean comparisons revealed that native Pacific and invasive Atlantic lionfish responded similarly to measured environmental factors (Table 1). Hunting activity was greatest when overcast (Table 1), and this response to changes in cloud cover was most evident for lionfish on Guam and the Bahamas (Fig. 5a). Together with the Caymans, these 2 regions were sampled at shallower depths (mean \pm SEM: Philippines $=19.3 \pm 0.3 \mathrm{~m}$, Guam $=10.9 \pm$ $0.4 \mathrm{~m}$, Cayman Islands $=9.4 \pm 0.3 \mathrm{~m}$, Bahamas $=3.1 \pm$ $0.1 \mathrm{~m}$; Kruskal-Wallis $H=925.1, \mathrm{df}=3,1146, \mathrm{p}<$ 0.001), where the effects of cloud cover on ambient light levels were most obvious to the observers. High currents had a consistent effect across all regions, resulting in less time spent hunting and greater inactivity when compared to both low and medium currents (Table 1), especially on Guam (Fig. 5b). Habitat had only slightly significant effects in both inactivity and hunting patterns (Table 1, Fig. 5c). However, lionfish in rock/boulder habitats tended to hunt less and be more inactive, in contrast to lionfish over hard coral and sand/ rubble, where hunting peaked, especially in the Atlantic (Fig. 5c).

When all variables were examined simultaneously, hierarchical partitioning analyses indicated that time-of-day, followed by depth and habitat, were most important in explaining variation in lionfish behavior (Table 1). Although coefficient estimates for depth in the logistic model were not significant, depth accounted for almost $20 \%$ of total model deviance (Table 1) and coefficient estimates indi- 
Table 2. Reef-fish and crustacean prey targeted by lionfish Pterois volitans (based on strikes, but not necessarily kills) while hunting in their native Pacific and the invaded Atlantic. Shown are species (or taxa when species identification was not possible) targeted with an indication of whether each prey type was accessible to lionfish in the Atlantic, Pacific or both, and with their respective species-specific successful kill rates. The unidentified category includes both fishes and crustaceans. nt: not targeted; -: not available

\begin{tabular}{|c|c|c|c|c|c|c|c|}
\hline \multirow{3}{*}{$\begin{array}{l}\text { Subphylum/ } \\
\text { Superclass }\end{array}$} & \multirow{3}{*}{ Family } & \multirow{3}{*}{$\begin{array}{l}\text { Species/ } \\
\text { taxa }\end{array}$} & \multirow{3}{*}{ Access } & \multicolumn{4}{|c|}{ — $\%$ Success } \\
\hline & & & & \multicolumn{2}{|c|}{$\longrightarrow$ Pacific -} & \multicolumn{2}{|c|}{$\longrightarrow$ Atlantic } \\
\hline & & & & Philippines & Guam & Caymans & Bahamas \\
\hline Crustacea & & Mysidacea & Both & nt & nt & 50 & nt \\
\hline \multirow[t]{23}{*}{ Osteichthyes } & Acanthuridae & Acanthurus nigricans & Pacific & nt & 0 & - & - \\
\hline & Apogonidae & Apogon townsendi & Atlantic & - & - & 100 & nt \\
\hline & & Apogon sp. & Pacific & 0 & 0 & - & - \\
\hline & & Cheilodipterus sp. & Pacific & 0 & nt & - & - \\
\hline & Blenniidae & Malacoctenus triangulatus & Atlantic & - & - & 100 & nt \\
\hline & & Meiacanthus atrodorsalis & Pacific & nt & 0 & - & - \\
\hline & Gobiidae & Coryphopterus glaucofraenum & Atlantic & - & - & 100 & 75 \\
\hline & & Unidentified goby & Both & 0 & 0 & 100 & nt \\
\hline & Grammatidae & Gramma loreto & Atlantic & - & - & 0 & nt \\
\hline & Labridae & Halichoeres bivittatus & Atlantic & - & - & nt & 50 \\
\hline & & Halichoeres garnoti & Atlantic & - & - & 100 & 0 \\
\hline & & Labroides dimidiatus & Pacific & 0 & nt & - & - \\
\hline & & Thalassoma bifasciatum & Atlantic & - & - & - & 33 \\
\hline & Plotosidae & Plotosus lineatus & Pacific & 0 & nt & - & - \\
\hline & Pomacentridae & Chromis recruits & Pacific & 50 & nt & - & - \\
\hline & & Pomacentrus coelestis & Pacific & nt & 0 & - & - \\
\hline & & Stegastes partitus & Atlantic & - & - & nt & 100 \\
\hline & Scaridae & Scarus iserti & Atlantic & - & - & nt & 75 \\
\hline & & Sparisoma aurofrenatum & Atlantic & - & - & nt & 100 \\
\hline & & Unidentified parrotfish & Atlantic & - & - & 0 & nt \\
\hline & Serranidae & Serranus tigrinus & Atlantic & - & - & 0 & nt \\
\hline & Tetraodontidae & Canthigaster rostrata & Atlantic & - & - & 0 & 0 \\
\hline & Trichonotidae & Trichonotus elegans & Pacific & 100 & nt & - & - \\
\hline Unidentified & & & Both & 36.2 & 29.2 & 20.9 & 22.7 \\
\hline
\end{tabular}

cated a trend towards greater time spent hunting with increasing depth $(\beta=0.028, p=0.499)$ (Table 1).

\section{DISCUSSION}

Despite initial expectations of interoceanic differences in lionfish behavior related to native vs. invasive status, our field observations from 2 regions in each of 2 oceans suggest that overall patterns in lionfish time budgets, daily activity patterns, and success rates at killing prey are similar in the native Pacific and the invaded Atlantic. These results show that if ease of prey capture is higher for invasive lionfish due to naïve prey, this is not reflected in either kill rates, hunting time or crepuscular hunting patterns.

Instead, lionfish behavioral patterns are determined more by regional differences in a suite of environmental factors, which act synergistically to affect behavior. The most pronounced of these factors was the low light level associated with crepuscular times, during which time spent hunting was maximal, re- gardless of ocean of residence. Twilight foraging is a feature common among coral-reef piscivores, and is probably related to the advantages that low light levels confer to predators vs. their prey (Helfman 1986). The largely crepuscular hunting pattern found, despite peaks occurring in either sunrise and sunset (Guam and Bahamas) or sunrise alone (Philippines and Caymans), confirms earlier descriptions of lionfish in both their native range (Fishelson 1975, Myers 1999) and invaded range (Green et al. 2011).

\section{Between-ocean differences}

While lionfish time budgets and kill rates did not vary appreciably between oceans, there were nonetheless differences in diet breadth, prey size and use of blowing behavior between the native and invaded ranges. Although coral-reef fishes are far more diverse in the Pacific than in the Atlantic (Roberts et al. 2002), we observed invasive lionfish successfully consuming a broader diversity of fishes in the 
a

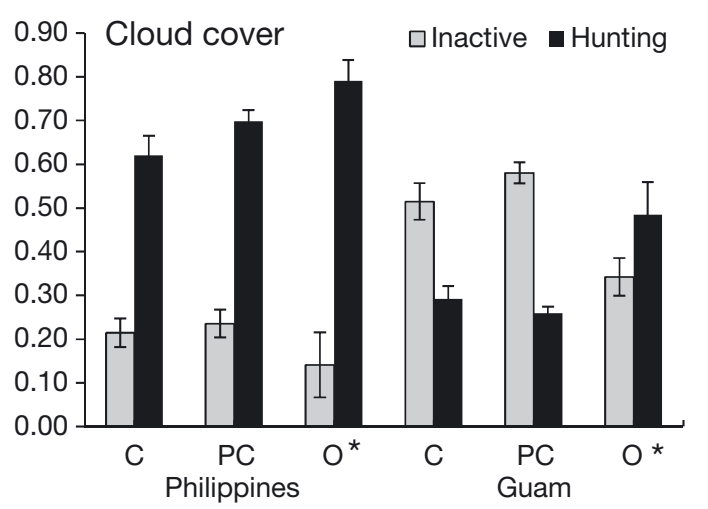

b

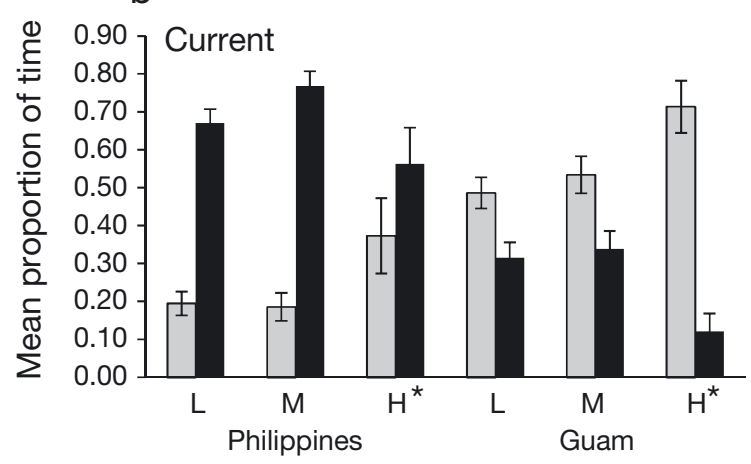

C

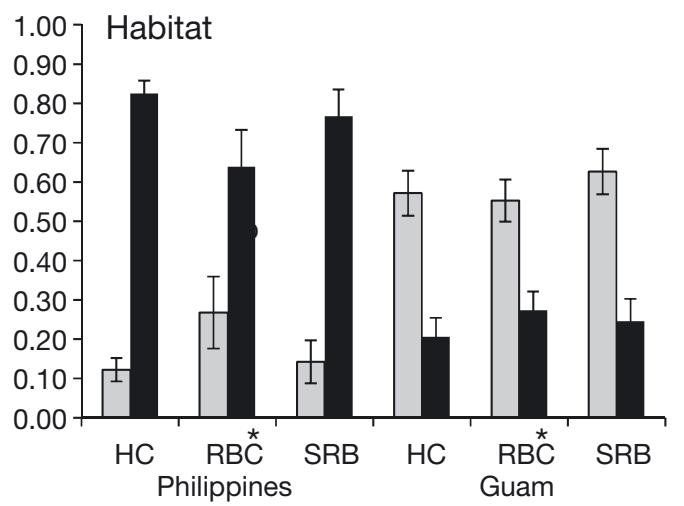

Pacific
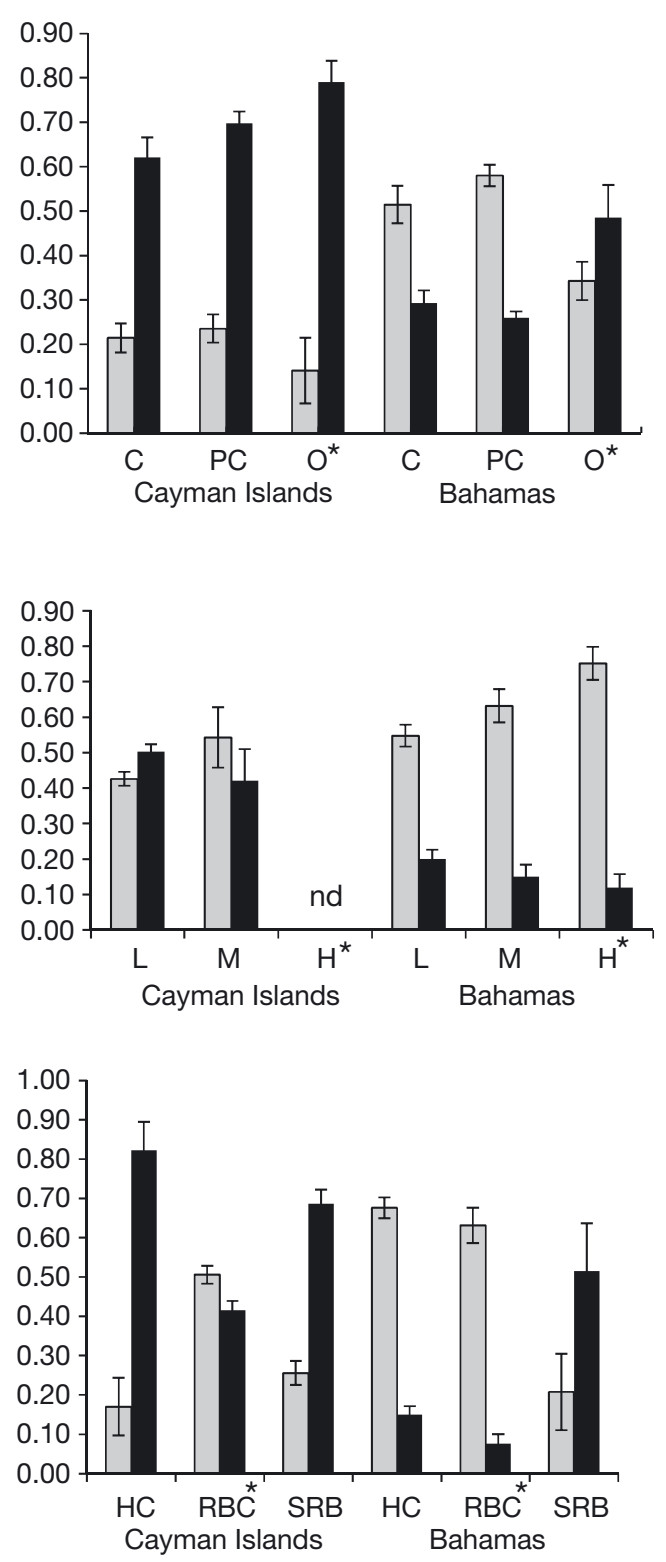

Atlantic

Fig. 5. Pterois volitans. Mean $( \pm$ SEM) proportion of time lionfish spent inactive or hunting in relation to (a) cloud cover (C: clear; PC: partly cloudy; O: overcast), (b) water current level (L: low; M: medium; H: high); and (c) habitat (HC: hard coral; RBC: rock-boulder/cave; SRB: sand/rubble) in the native Pacific (left) and invaded Atlantic (right). Asterisks next to letters $(\mathrm{H}, \mathrm{O}$ and $\mathrm{RBC}$ ) represent significant differences in overall activity levels at this level for each environmental factor $(\mathrm{p}<0.05$; see Table 1). nd: no data

Atlantic than native lionfish in the Pacific. Diet was broader in the Atlantic despite the fact that lionfish strikes were directed at a greater diversity of prey in the Pacific. Atlantic prey species composition was similar to that previously observed in Bahamian lionfish (Albins \& Hixon 2008, Morris \& Akins 2009). We observed only invasive lionfish consuming parrotfishes (Scaridae). Parrotfishes are ecologically impor- tant herbivores that help to keep seaweeds from overgrowing corals (Mumby 2006). Declines in such herbivores in the invaded range could have severe indirect effects on Atlantic coral reefs (Albins \& Hixon 2011).

There are at least 3 possible (not mutually exclusive) explanations for increased diet breadth in invasive relative to native lionfish. The first is based on 
optimal foraging theory, which predicts that diet breadth is determined by the encounter rate of preferred prey (Stephens \& Krebs 1986). It is possible that crustaceans and juvenile pomacentrids are preferred prey in the Pacific and are present in sufficiently high densities that diet breadth is reduced in native Pacific lionfish. The higher availability of fish recruits during the dates we sampled in the Philippines (Abesamis \& Russ 2010) compared to other regions is consistent with this hypothesis, yet the fact that lionfish targeted a greater diversity of prey in the Pacific but successfully killed a lower diversity of prey, tends to falsify this hypothesis.

A second explanation is that prey are naïve to lionfish as a novel predator in the newly invaded Atlantic, allowing generalist lionfish to successfully capture a broader diversity of prey, even when kill rates and hunting times were equal between native and invaded locations. This explanation is in line with our initial hypothesis that invasive lionfish would consume greater variety of prey given the lack of native prey defenses. As observed for invasive lionfish (Albins \& Hixon 2008, Green et al. 2011), native prey may exhibit weak or nonexistent responses to newly introduced predators (Cox \& Lima 2006, Smith et al. 2008). Lionfish are new to the Atlantic and do not resemble any native Atlantic predators. Therefore, prey types that normally may not be available to native Pacific lionfish are present in invasive lionfish diet. Our findings of broader targeted species in the native Pacific Ocean, yet greater success at killing more diverse prey in the Atlantic, lends credence to this hypothesis. The prey naïveté explanation is also supported by the larger prey size accessed by invasive lionfish. It is possible that, because prey in the Pacific are more likely to recognize lionfish as predators, only the smallest and/or least mobile species and individuals are vulnerable to predation. Still further evidence of prey naïveté in the invaded range comes from differences in the use of blowing behavior by lionfish. Lionfish employed blowing while stalking prey 3 times more often in the native Pacific range compared to the invaded Atlantic range. Blowing behavior may confuse prey and facilitate headfirst capture as prey face upcurrent (Albins \& Lyons 2012). Greater use of this hunting technique may be required in the Pacific because prey recognize lionfish and are more wary. In contrast, because lionfish are new to the Atlantic, they need not employ such secondary hunting methods as frequently to capture naïve Atlantic prey. Given that native prey can adapt to invasive predators by rapid evolution of behavioral responses to predator presence (Schlaepfer et al.
2005, Freeman \& Byers 2006), we suggest that future research focus on whether invasive lionfish and native prey alter their attack and evasion behavior, respectively, through time.

A third explanation for increased diet breadth in invasive relative to native lionfish is the competitive and/or predatory release that often accompanies invasions (Mack et al. 2000). For example, the introduced grouper Cephalopholis argus fed on larger prey as a response to lower competitor densities in non-native vs. native reefs (Meyer \& Dierking 2011). A similar pattern could affect lionfish hunting, given the larger prey sizes consumed at invaded reefs and the higher diversity of ecologically similar reef fishes (i.e. potential competitors) in the native Pacific relative to the invaded Atlantic (Roberts et al. 2002). Additionally, Albins (2012) has demonstrated that invasive lionfish compete effectively with native grouper. Regarding release from predation, although venomous spines appear to be an effective prey defense for larger lionfish (Allen \& Eschmeyer 1973), we hypothesize that new lionfish recruits (which have flexible spines with less venom) may be the target of co-evolved, specialized, smaller predatory fishes in the Pacific that do not occur in the Atlantic, thereby providing a source of biotic control that may be absent in the Atlantic.

\section{CONCLUSIONS}

Generally, lionfish are crepuscular predators in both their native Pacific and invaded Atlantic ranges. Invasive lionfish seem to have maintained their native behaviors that generally vary with environmental conditions, and therefore display no major inter-ocean differences in overall activity patterns. Lionfish nonetheless exhibit substantial behavioral and ecological differences between Pacific and Atlantic locations. First, invasive lionfish spend far less time using blowing behavior, perhaps indicating prey naïveté in the Atlantic. Second, invasive lionfish have far broader diets (measured by kill rates) despite the fact that (1) native lionfish hunted greater variety of prey, and (2) the Pacific Ocean supports a far greater species diversity of potential prey reef fishes. Importantly, only invasive lionfish were observed consuming ecologically important parrotfishes. Third, Atlantic prey of lionfish are larger, even though prey consumption rates are comparable to native Pacific lionfish, therefore implying that invasive lionfish ingest a greater daily ration in terms of prey biomass than do native lionfish. Overall, it is 
clear that red lionfish display a substantial capacity for behavioral adaptation to local environmental conditions, likely contributing to their enormous success as an invasive species.

Acknowledgements. We are immensely grateful to J. Miller, D. Inocencio, and G. Scheer for help with field work, $\mathrm{K}$. Ingeman for reviewing the manuscript, and M. Albins for general advice. Staffs of the Perry Institute for Marine Science (Bahamas) and the Central Caribbean Marine Institute (Caymans) provided logistic support. R. Abesamis and R. Jadloc assisted with logistics in the Philippines. Statistical advice from A. Halford and A. Kerr was invaluable for dealing with a complex dataset. This research was funded by US National Science Foundation grants 08-51162 and 12-33027 to M.A.H., and a University of Guam Micronesian Area Research Center (MARC) scholarship to K.C.

\section{LITERATURE CITED}

Abesamis RA, Russ GR (2010) Patterns of recruitment of coral reef fishes in a monsoonal environment. Coral Reefs 29:911-921

Albins MA (2012) Effects of invasive Pacific red lionfish Pterois volitans versus a native predator on Bahamian coral-reef fish communities. Biol Invasions doi:10.1007/ s10530-012-0266-1

Albins MA, Hixon MA (2008) Invasive Indo-Pacific lionfish Pterois volitans reduce recruitment of Atlantic coral-reef fishes. Mar Ecol Prog Ser 367:233-238

Albins MA, Hixon MA (2011) Worst case scenario: potential long-term effects of invasive predatory lionfish (Pterois volitans) on Atlantic and Caribbean coral-reef communities. Environ Biol Fish doi:10.1007/s10641-011-9795-1

Albins MA, Lyons PJ (2012) Invasive red lionfish Pterois volitans blow directed jets of water at prey fish. Mar Ecol Prog Ser 448:1-5

Allen GR, Eschmeyer WN (1973) Turkeyfishes at Eniwetok. Pac Discovery 26:3-11

Anderson MJ, Gorley RN, Clarke RK (2008) PERMANOVA+ for PRIMER: Guide to software and statistical methods. Primer-E, Plymouth

> Andrews KS, Williams GD, Farrer D, Tolimieri N, Harvey CJ, Bargmann G, Levin PS (2009) Diel activity patterns of sixgill sharks, Hexanchus griseus: the ups and downs of an apex predator. Anim Behav 78:525-536

Bates D, Maechler M, Bolker B (2011) Linear mixed-effects models using S4 classes. Package lme4. R Foundation for Statistical Computing, Vienna. http://lme4.r-forge. r-project.org/

Belovsky GE, Slade JB (1986) Time budgets of grassland herbivores: body size similarities. Oecologia 70:53-62

- Bernadsky G, Goulet D (1991) A natural predator of the lionfish, Pterois miles. Copeia 230-231

> Chen WM, Purser J, Blyth P (1999) Diel feeding rhythms of greenback flounder Rhombosolea tapirina (Günther 1862): the role of light-dark cycles and food deprivation. Aquacult Res 30:529-537

Côté IM, Maljković A (2010) Predation rates of Indo-Pacific lionfish on Bahamian coral reefs. Mar Ecol Prog Ser 404: 219-225

Cox JG, Lima SL (2006) Naïveté and an aquatic-terrestrial dichotomy in the effects of introduced predators. Trends Ecol Evol 21:674-680

Fishelson L (1975) Ethology and reproduction of pteroid fishes found in the Gulf of Aqaba (Red Sea), especially Dendrochirus brachypterus (Cuvier) (Pteroidae, Teleostei). PSZN I: Mar Ecol 39:635-656

> Fishelson L (1997) Experiments and observations on food consumption, growth and starvation in Dendrochirus brachypterus and Pterois volitans (Pteroinae, Scorpaenidae). Environ Biol Fishes 50:391-403

Freeman AS, Byers JE (2006) Divergent induced responses to an invasive predator in marine mussel populations. Science 313:831-833

Green SJ, Côté IM (2008) Record densities of Indo-Pacific lionfish on Bahamian coral reefs. Coral Reefs 28:107

Green SJ, Akins JL, Côté IM (2011) Foraging behavior and prey consumption in the Indo-Pacific lionfish on Bahamian coral reefs. Mar Ecol Prog Ser 433:159-167

Green SJ, Akins JL, Maljković A, Côté IM (2012) Invasive lionfish drive Atlantic coral reef fish declines. PLoS ONE 7:e32596

> Guo Q (2006) Intercontinental biotic invasions: What can we learn from native populations and habitats? Biol Invasions 8:1451-1459

> Hansen EA, David BO, Closs GP (2004) Diel patterns of feeding and prey selection in giant kokopu (Galaxias argenteus). NZ J Mar Freshw Res 38:341-345

Helfman GS (1986) Fish behaviour by day, night and twilight. In: Pitcher TJ (ed) Behavior of teleost fishes. Chapman \& Hall, London, p 479-512

Holway DA, Suarez AV (1999) Animal behavior: an essential component of invasion biology. Trends Ecol Evol 14: 328-330

Kulbicki M, Beets J, Chabanet P, Cure K and others (2012) Distributions of Indo-Pacific lionfishes Pterois spp. in their native ranges: implications for the Atlantic invasion. Mar Ecol Prog Ser 446:189-205

> Lesser MP, Slattery M (2011) Phase shift to algal dominated communities at mesophotic depths associated with lionfish (Pterois volitans) invasion on a Bahamian coral reef. Biol Invasions 13:1855-1868

- Mack RN, Simberloff D, Lonsdale WM, Evans H, Clout M, Bazzaz FA (2000) Biotic invasions: causes, epidimiology, global consequences, and control. Ecol Appl 10:689-710

> MacNally R (1996) Hierarchical partitioning as an interpretative tool in multivariate inference. Austral Ecol 21: 224-228

Maljković A, Van Leeuwen T (2008) Predation on the invasive red lionfish, Pterois volitans (Pisces: Scorpaenidae), by native groupers in the Bahamas. Coral Reefs 27:501

> Meyer AL, Dierking J (2011) Elevated size and body condition and altered feeding ecology of the grouper Cephalopholis argus in non-native habitats. Mar Ecol Prog Ser 439:203-212

- Morris JA, Akins JL (2009) Feeding ecology of invasive lionfish (Pterois volitans) in the Bahamian archipelago. Environ Biol Fishes 86:389-398

Morris JA, Whitfield PE (2009) Biology, ecology, control and management of the invasive Indo-Pacific lionfish: an updated integrated assessment. Tech Mem NOS NCCOS 99. National Oceanic and Atmospheric Administration, Washington, DC

$>$ Mumby PJ (2006) The impact of exploiting grazers (Scaridae) on the dynamics of Caribbean coral reefs. Ecol Appl 16:747-769 
Myers R (1999) Micronesian reef fishes: a field guide for divers and aquarists. Coral Graphics, Barrigada/Guam

Peng CJ, Lee KL, Ingersoll GM (2002) An introduction to logistic regression analysis and reporting. J Educ Res 96: 3-14

Quinn GP, Keough MJ (2002) Experimental design and data analysis for biologists. Cambridge University Press, New York, NY

Randall J (2005) Reef and shore fishes of the South Pacific: New Caledonia to Tahiti and the Pitcairn Islands. University of Hawaii Press, Honolulu, HI

R Development Core Team (2010) R: a language and environment for statistical computing. R Foundation for Statistical Computing, Vienna, www.R-project.org

Reebs SG (2002) Plasticity of diel and circadian activity rhythms in fishes. Rev Fish Biol Fish 12:349-371

Roberts CM, McClean CJ, Veron JEN, Hawkins JP and others (2002) Marine biodiversity hotspots and conservation priorities for tropical reefs. Science 295:1280-1284

Rossiter DG, Loza A (2010) Technical note: analyzing land cover change with logistic regression in R. Faculty of Geo-Information Science \& Earth Observation, University of Twente, Enschede. www.itc.nl/ rossiter/teach/R/ R_lcc.pdf

Schlaepfer MA, Sherman PW, Blossey B, Runge MC (2005) Introduced species as evolutionary traps. Ecol Lett 8: 241-246

Schofield P (2009) Geographic extent and chronology of the invasion of non-native lionfish (Pterois volitans [Linnaeus 1758] and $P$. miles [Bennet 1828]) in the Western

Editorial responsibility: Charles Birkeland,

Honolulu, Hawaii, USA
North Atlantic and Caribbean Sea. Aquat Invasions 4: 473-479

Schofield P (2010) Update on geographic spread of invasive lionfishes (Pterois volitans [Linnaeus 1758] and P. miles [Bennet 1828]) in the Western North Atlantic Ocean, Caribbean Sea and Gulf of Mexico. Aquat Invasions 5: S117-S122

Semmens BX, Buhle ER, Salomon AK, Pattengill-Semmens CV (2004) A hotspot of non-native marine fishes: evidence for the aquarium trade as an invasion pathway. Mar Ecol Prog Ser 266:239-244

Smith GR, Boyd A, Dayer CB, Winter KE (2008) Behavioral responses of American toad and bullfrog tadpoles to the presence of cues from the invasive fish, Gambusia affinis. Biol Invasions 10:743-748

Stephens DW, Krebs JR (1986) Foraging theory. Princeton University Press, Princeton, NJ

Valdez-Moreno M, Quintal-Lizama C, Gómez-Lozano R, García-Rivas MC (2012) Monitoring an alien invasión: DNA barcoding and the identification of lionfish and their prey on coral reefs of the Mexican Caribbean. PLoS ONE 7:e36636

Walsh C, Mac Nally R (2008) hier.part: Hierarchical partitioning, $\mathrm{R}$ package version 1.0-3. R Foundation for Statistical Computing, Vienna. http://cran.r-project.org/web/ packages/hier.part/index.html

- Whitfield PE, Hare JA, David AW, Harter SL, Muñoz RC, Addison CM (2007) Abundance estimates of the IndoPacific lionfish Pterois volitans/miles complex in the Western North Atlantic. Biol Invasions 9:53-64

Submitted: March 23, 2012; Accepted: July 16, 2012

Proofs received from author(s): October 8, 2012 